\title{
My Front Row Seat Part IV
}

\section{Further Encounters at the Greatest Show on EArth}

\author{
Henry J.M. Barnett
}

Can. J. Neurol. Sci. 2010; 37: 562-567

This is part of a memoir that was not intended as a neurological journal contribution but it has so evolved. My theme, if there has truly been one, was to point out to those who would aspire to a long medical career, if lucky, energetic and dedicated, they may look forward to a life filled with interest, not the least of which are encounters with both patients and discoveries of great interest, but also of remarkable people, some in a great variety of strange places. Some who are featured were encountered during professional commitments, others with family. For convenience they will be dealt with geographically rather than temporally. I will begin this part by discussing personalities and discoveries from Canada, plainly best known to me.

Joey Smallwood led Newfoundland and Labrador away from its 400 centuries of British colonial exploitation to become Canada's tenth province (almost 100 years after the others had joined together). He was a man who wished to present himself as a "peoples' person". In 1964 Kay and our four children went on a camping trip that took us across the width of our new province on the barely completed transcontinental highway from Cornerbrook to St. John's. We spotted the famous man entering the government office building: "How would you kids like to meet a famous Canadian?" His secretary was somewhat taken aback with the request but he came out from his "Oval Office" to greet effusively six moderately dowdy campers, one (Ian) still smeared here and there with the lime dust provided for use in the nearby campsite's outdoor privy. To our delight the friendly Joey, shook hands all around and then apologizing that he had a busy schedule, went back inside. If charisma trumps other qualities in a politician he had his share.

Smallwood decided that a country consisting of scores of fishing outports scattered along its lengthy and tortuous coastline connected to each other only by ships, could never provide reasonable educational or medical care facilities. With his usual energy and initiative he set out a plan to consolidate the population, discouraging the persistence of tiny but truly isolated communities. In this 1964 camping excursion we were witness to whole houses being transported on barges pulled by tug-boats in the Straits of Belle Isle as part of this resettlement. In 1965 I served part of a summer as a volunteer physician on the Grenfell Outport Hospital Ship, based at St. Anthony at the tip of the Northern Peninsula. We weathered rough seas in storms, and in fog watched for icebergs. We were several days fog-bound in Red Bay, Labrador. One evening the fog abruptly lifted: "Hey, Doc, how would you like to bring your son and we will go to Black Duck (population=2). It's 20 miles and the sun does not set until 11. The old man there has a sealing gun you might buy."
We got there in a fishing dory in an hour, had our second dinner of the day and our first dinner of salted porpoise, prepared by his octogenarian wife. And for $\$ 10.00$ (double the asking price) I bought the six-foot long muzzle-loading antique, which had been used by him as a youth and by his father to hunt seal, and the common waterfowl of Labrador (Eiders and Murres) (Figure 1). At 10:30, we left in our boat and within two minutes the fog descended like a curtain.

Son Will's job was to sit in the bow and watch for the fluorescence produced in a line toward shore from the rope holding the salmon nets and shout so that the propeller of the outboard motor would be lifted clear. We were worried but the fishermen were calm and unconcerned. We crept along mostly within earshot of the Red Bay foghorn and by striking matches the compass was checked. All watched in the gloom for icebergs. At about midnight we ran out of matches and a rocky island muffled the foghorn but the reassuring word was "we can manage by watching the wave action". At 1:30 am a very bright white light appeared above us on the shore. As we passed, it was gone and then another appeared followed by a series of vanishing lights. We were being guided into the entrance to the harbor by what I came to call "Neighborhood Watch, Labrador style". When Will thanked people the next morning for guiding us in, their attitude seemed to be "Don't be silly what else would you expect? The whole village knew the doctor was out there in the fog".

Pierre Trudeau, our last charismatic Prime Minister, visited London to check on a favored cabinet colleague under my care who had a non-dominant hemisphere stroke due to a carotid artery dissection, a condition of which the fuller elucidation yet lay ahead. The great man was warm, gentle but sufficiently curious that we had to journey together to the radiology department so that he might see for himself and discuss with the radiologists the arteriogram visualizing the blockage of the right carotid artery and discuss the significance of the visible collateral circulation. Recovery was adequate in the long run so that the patient was able to accept a Senate seat which he held

Received February 24, 2010. Final Revisions Submitted March 10, 2010. Correspondence to: Henry J.M. Barnett, (Professor Emeritus, University of Western Ontario), 14865 Concession 7, King City, Ontario, L7B 1K4, Canada. 


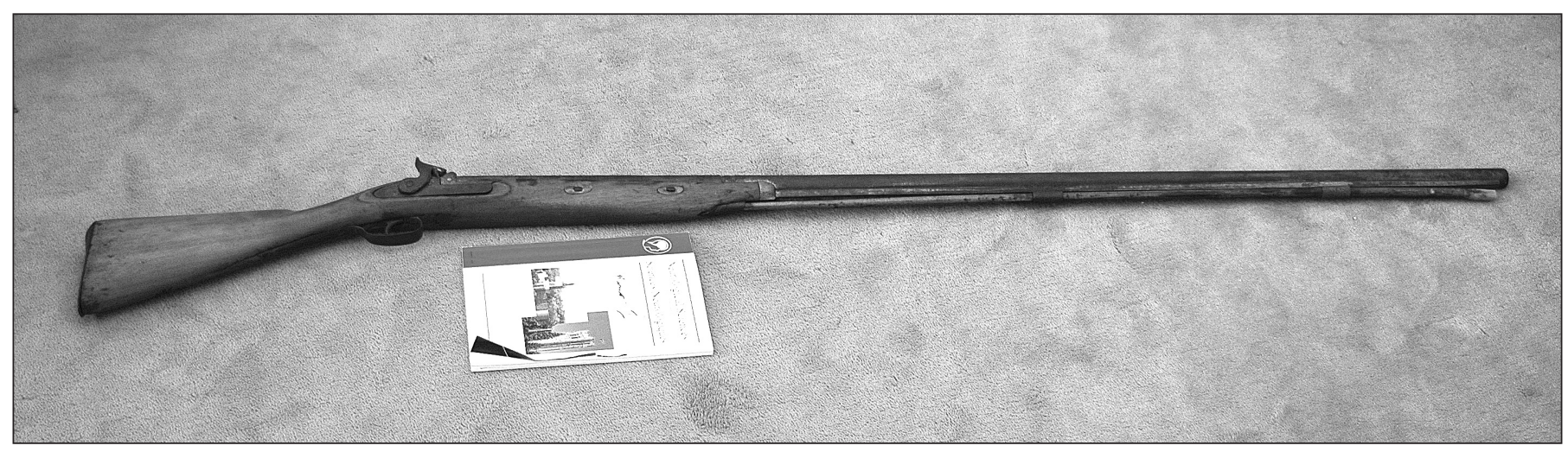

Figure 1: An antique sealing gun from the disappearing settlement of Black Duck in Labrador. (Copy of the Journal for sizing)

for a number of years. Secretarial exchanges had already betrayed the fact that in waiting to visit with him I could miss my scheduled flight to Minneapolis to deliver an invited lecture. "No worry, tell him I'll have my plane pick him up at the London airport and get there within a few minutes of lecture time". True to his word at first light the next morning I boarded a two jetengine, two-pilot plane at London airport. I learned later that the waiting audience was advised of the exact time of my slightly belated arrival and that I was traveling on the Prime-Minister's private jet. Maybe they thought this was an extension of the friendly Canadian way of customarily conducting our affairs!

In both of these Canadians, vanity was lacking. They were not humble but they were modest, the important differential characteristics of which I had come to appreciate. Two departed colleagues on the cardiology staff of the Toronto General Hospital were admirably modest but nevertheless their work made major changes in the universal practice of cardiology around the globe. Bob MacMillan and Ken Brown, in the early 1960's introduced the concept of Coronary Care Units with 24hour monitoring of vital functions, starting initially and particularly with the monitoring of cardiac rhythm. This monitoring practice in Coronary Care Units expanded over the years has become every-day, has spread to all countries with any semblance of good health care. We take it for granted. It all started in a small two-bed room on Public Ward G of the Toronto General Hospital (TGH). Cardiologists beat a path here from all continents to observe this advance. Probably no major leap forward in medical practice occurred with less fanfare, less media attention and so little by way of rousing acclaim.

Red and white blood cells were a scientific fascination from the time of the discovery of the microscope. The third formed element in the blood, the platelets were studied less and imperfectly understood. Only modest research time was dedicated to them until after WWII. Possibly because of this enigmatic and neglected position in our medical research efforts, a dynamic Torontonian, Fraser Mustard seized the problem and devoted at least two decades to their intensive study. With colleagues Hugh Smyth and Metro Ogryzlo he studied the origins of platelets in the bone-marrow, their life-cycle, their role in thrombus formation and finally detected two commonly used drugs (one an anti-gout remedy, sulfinpyrazone and the other a common analgesic anti-inflammatory agent, aspirin) that would alter the platelet function and both would inhibit plateletinitiated thrombus formation. As this work proceeded clumped platelets were recognized in the retinal arterioles in patients with amaurosis fugax, in progressive cerebral vascular thrombi, in the cortical arteries on the exposed brain surface (Figure 2) and at a later time in the intramyocardial coronary artery branches at post-mortem in patients dying with unstable angina. Realizing the connection between his observations and these phenomena

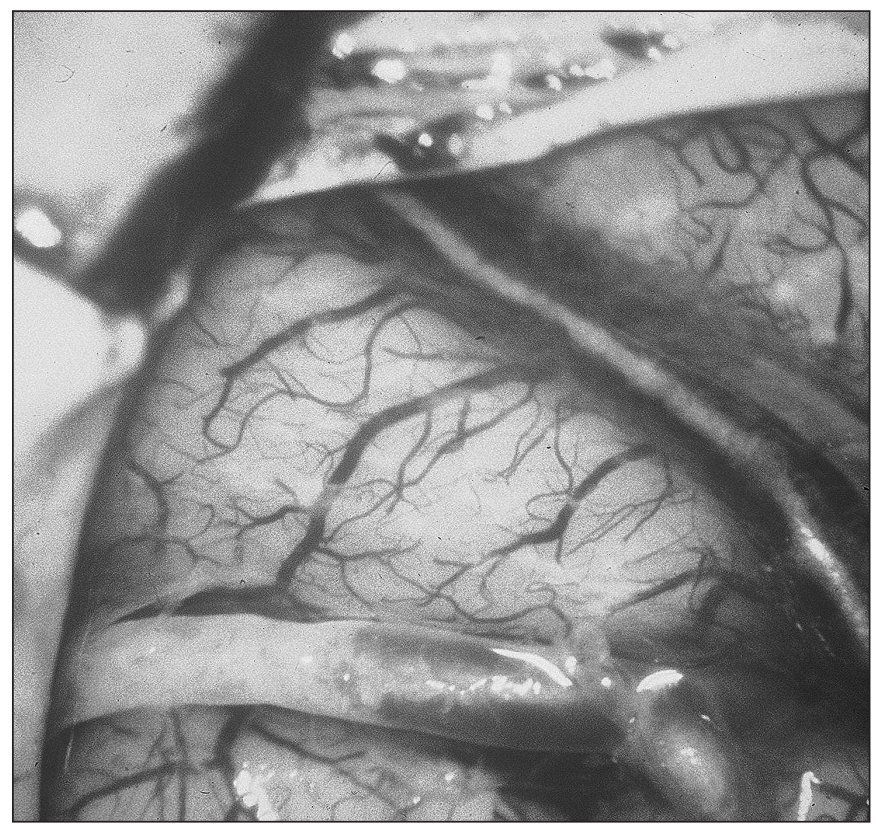

Figure 2: White platelet material in a cortical branch of the MCA in a patient undergoing STA/MCA anastomosis. Down stream was an occlusion of the internal carotid artery. 
indicative of impending or developed cerebral and cardiac events, the era of aspirin prophylaxis for preventing ischemic stroke and myocardial infarction was sparked thanks to Mustard. My role in this saga has been described in Memoir I. In the planning stages Mustard brought to the table a team of experts in biostatistics and methodology from McMaster Medical School led ethically and intellectually by David Sackett. Plateletinhibition became and persists as a widespread therapeutic and prophylactic strategy.

Heparin was isolated from the liver in the early 20's at Johns Hopkins Hospital. For years many laboratories attempted to produce from it a safe biological product. Finally in mid-40's this was achieved by Charles Best, adding to his laurels as the codiscoverer of insulin. What a record for a single dedicated individual! Safe and reliable heparin made open-heart surgery feasible under my hero Bill Bigelow as it did renal dialysis, (promoted by Gordon Murray and my class-mate WTW Clarke), organ transplantation (with survival ensured by the Borel/Stiller alliance) and became standard treatment for pelvic and upper limb or crural thrombi threatening pulmonary emboli (studied initially under our sparkling surgeon-teacher: Gordon Murray).

Two exciting discoveries changed medical practice because the trained minds of two of my colleagues were ready to query and follow the unexpected: First an extract of the periwinkle plant was said in native Jamaican medicine to be a diabetic therapy. Banting suggested to Bob Noble of University of Western Ontario (UWO) that he might investigate this alleged benefit. He did and the resultant brew of the Rose Periwinkle was found not to bring down the blood sugar but to suppress lymphocytes. Noble and Harold Warwick postulated that it might have therapeutic value in lymphatic and leukemic cancers. Fifty years earlier Ehrlich had introduced chemical therapy now usually abbreviated to chemotherapy for the specific disease of syphilis-combining bismuth and arsenic. A second and most important major era of chemotherapy was about to be introduced. It gave to those afflicted with lymphatic cancer, Hodgkin's disease and lymphatic leukemia many years of normal life by using the periwinkle extract in a form originally known as vinkoleukoblastin. In minimally modified form and renamed vincristin, it persists as standard and useful best therapy where there was nothing effective prior to this. Thousands of useful years have been added to scores of thousands of lives.

A second notable discovery had a remarkably similar serendipitous beginning. A European drug firm routinely asked its traveling staff to scoop up sterile samples of foreign soil (in this instance Norway) in their quest for a new micro-organism that might harbor antibiotic properties. Nothing like this emerged but when a sample of this spore-bearing fungus was tested by their scientist Jean Borel, it had no antibiotic properties but lymphocytes were depressed. After suitable toxicity and safety testing Calvin Stiller in London proved the efficacy of what was identified as a spore-producing organism, cyclosporine, which suppresses "killer lymphocytes" and thus acts as post-transplant anti-rejection therapy. It persists as the standard agent in this vital role, permitting a modern miracle to restore life and sight in the presence of organ failure. Recently a local Toronto madman strangled his daughter to underscore his religious beliefs, not happily accepted by her. She was admitted brain-dead to the Toronto Sick Childrens' Hospital. She did not die totally in vain: her two kidneys, both lungs, two cornea, one heart and one liver were accepted by needy patients and none were rejected due to the protective use of cyclosporine in seven patients awaiting these vital new organs.

The common calls nowadays to preserve biodiversity could not be better argued than by the survival of the insignificant Jamaican plant plus the lack of indiscriminate pollution of Norway's soil by agricultural pesticides.

Douglas Wigle and I stood at the post-mortem table together in the late 40's. My job that particular day as a pathology research fellow doing post-mortem examinations was to ascertain why healthy-looking, albeit oversized heart muscle had led to fatal heart failure. None of the usual features that cause heart muscle to enlarge were to be found. We scratched and shook our heads and went on to the next mystery. Over time Wigle did not forget, remained puzzled and delineated the clinical features of a rare but recognizable form of heart muscle disease. In time surgical therapy became available for what he and a small cadre of other cardiologists in Boston described as Hypertrophic Cardiomyopathy. Persistence is important in scientific endeavor. He has emerged as the world's authority on this entity and its management and supervises the care of almost 1500 patients recognized to have this affliction.

Along with a series of visitors to the University of Moscow Department of Radiology in the 1970's went a Parisian neuroradiologist, Gerard Debrun. In common with other visitors the secretive Serbinenko showed him only "before and after" angiograms and photos of patients whom he had treated for traumatic carotid-cavernous fistulae. In common with previous visitors Debrun was denied access to the radiology suite but was able to conjecture that a catheter was inserted and a detachable balloon released and blown up within the fistula, obliterating it. Back in Paris Debrun and his technicians and engineers duplicated what they surmised had to be utilized and successfully repeated the striking Moscow results. Since we were a combined interdisciplinary department, the University Hospital Chief of Radiology permitted us to recruit and appoint Debrun to a dual appointment in the Clinical Neurosciences and Radiology Departments; ultimately this led to the training of Fox and Vinuela, and through them, Lee, Gulka, Peltz and Lownie all becoming experts of the nascent technology of cerebral interventional neuro-radiology. This started separately in New York (Barenstein) and in California (Hirashima). Through Lin and Lylak it expanded to South America and finally explosively to the entire medical world of prophylactic modern cerebral vascular disease. Developments in therapy of aneurysms, cerebral vascular malformations as well as fistulae have been of a revolutionary nature and led to non-invasive therapy on a regular basis to a large number of patients with these conditions. Whether it will replace carotid endarterectomy (CE) remains entirely speculative. Enthusiasm has consistently outstripped fact.

Two household names occupied the world-wide field of neurosurgery for decades. First was my lifelong colleague and friend Charles Drake who had the extra skill and made the keen observations necessary to deal safely with posterior fossa berry aneurysms. Wilder Penfield, founder of the Montreal Neurological Institute, was an early advocate of the value of surgical ablation of epileptogenic cortical lesions and on them 
and on other patients whose cortex was to be surgically exposed he made time-consuming and meticulous observations from stimuli on the awake patient and was able over decades of keeping such records to construct maps (homunculi) of the functional anatomy of the human brain. With colleagues, including the neuro-psychology pioneer, Brenda Milner, the entity of temporal lobe seizures was described and popularized. It remained for Sam Wiebe to utilize the modern methodology of randomized trials to prove the efficacy of temporal lobectomy combined with anticonvulsants in controlling disabling seizures in this common variety of epilepsy.

Assisted ventilation made feasible the introduction of short and long-term Intensive Care Units. To Bryan Young and Charles Bolton we are indebted for their identification of the neurological consequences of such prolonged life supportive measures. Their work has been detailed in many publications and the leading monograph on this subject, Tom Feasby, later to become Dean of Medicine at Calgary, working with Angelica Hahn on the inflammatory polyneuropathies were able to described the value of immunosupression for the Giillain-Barre Syndrome. They are credited also with being the first to recognize the axonal variant of Giillain-Barre Syndrome.

Andrew Kertesz has published leading monographs on his lifetime pursuit of cognitive afflictions, particularly studying

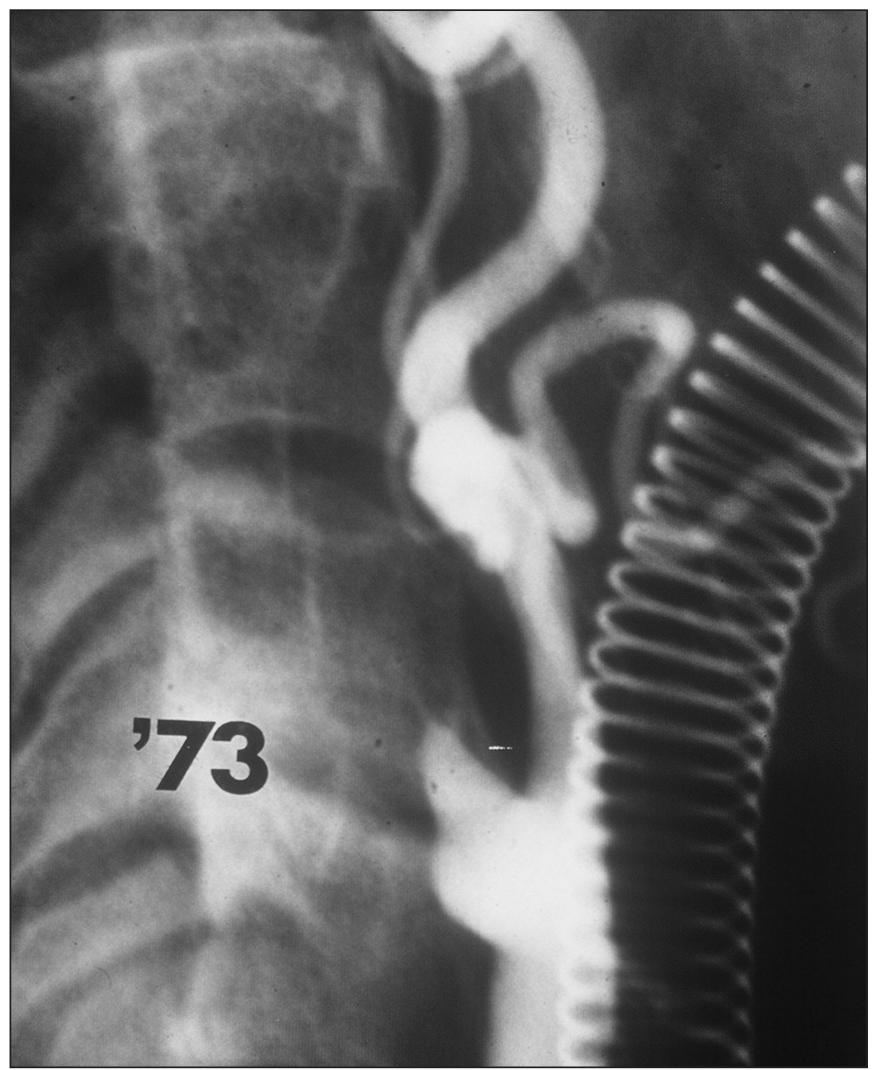

Figure 3: The irregular stump of an occluded ICA. dysphasic subjects and more recently newly recognized varieties of dementia, once lumped together under the rubric of Pick's Disease. To J. Alan Fox, we are indebted for his determination of the recognized standard measurement formula required to evaluate the degree of stenosis of the extracranial course of cerebral arteries and for his clear delineation of the radiological features of the condition of "near-occlusion" of the carotid artery.

A member jointly of the CNS and Pathology Departments at UWO, the recruit from South Africa, John Kaufman, provided the pathological proof needed to indicate without equivocation that the "stump" of an occluded carotid artery may accumulate platelet-fibrin and other thrombotic material that can pass up the anastomotic supply provided by the external carotid artery and result in an embolic stroke (Figures 3 and 4).

Because the Neuroscience Department at UWO was interdisciplinary and because all members knew of the special research pursuits of the others we were able to channel all patients to clinicians involved in subdivisions of research interest: cerebral vascular disease, epilepsy, neuromuscular disorders, speech disorders and multiple sclerosis. For the latter we started with Don Paty, added George Ebers, then John Noseworthy and George Rice. By this time we had the largest MS Clinic in the continent and were able to supply the needed patients and leadership to effectively put to rest claims for therapy that had passed through peer-review for top-flight journals but were not really good therapy as judged by rigorous clinical trials (acupuncture, cancer chemotherapy, and high pressure chamber therapy).

A particular feature of the CNS Department was our ability to add a larval group of clinicians who were specifically trained in the emerging specialty of neuro-oncology. All took basic neurology training with us and then neuro-oncolological experience with Jerry Posner in the Sloan Kettering Hospital in New York City. The Ontario Cancer Institute supported this

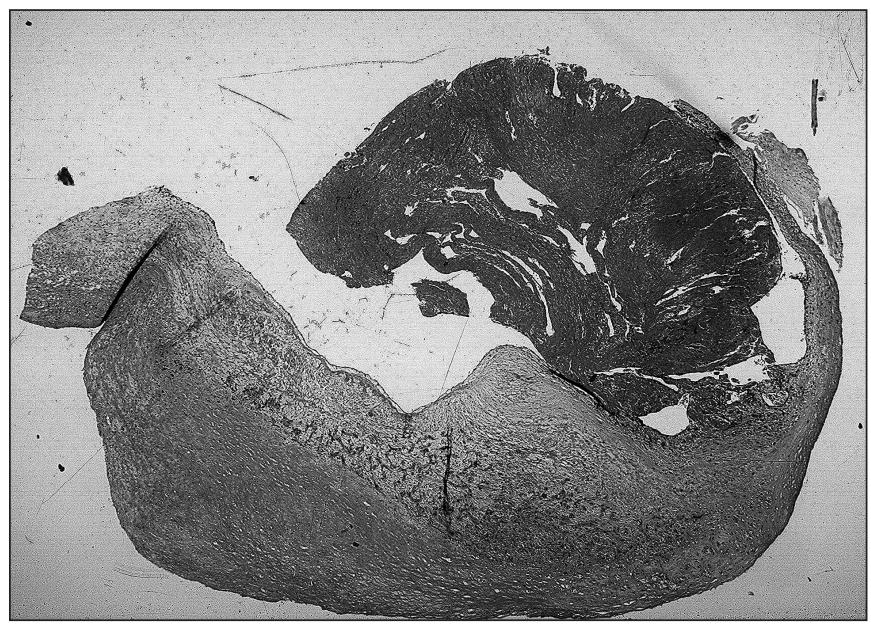

Figure 4: Thrombus attached to the atheromatous wall of the same artery as in figure 3, microscopically examined after "stumpectomy" (a procedure no longer recommended). 
novel departure. Greg Cairncross was the innovator, associated with David MacDonald and then Dwight Moulin. The latter was especially dedicated to cancer pain relief. Between the first two their main accomplishment was the discovery of the most effective combination of chemotherapy and radiation as a lifeprolonging formula for adding years to the functionally useful lives of patients with oligodendroglioma, the first breakthrough in managing any of the variants of brain astrocytoma.

Before proceeding to experiences in more distant places in my 65-year journey through medicine, I am moved to recount a few peculiar stories from the rich experience that is the practice of Neurology. Early one morning the bright-eyed resident at my 6:30 am Sunnybrook round in response to my: "Any interesting new patients?" "Yes but possibly a sad one". "Why so?" "He is very young but must have a brain tumor. He came down from Camp Borden because of a seizure experienced during military training and he has a hemianopia of which he is unaware. This could best be explained by the slow development of such a symptom, possibly a tumor of which he is also unaware." The reasoning was good but we went to the bedside, and confirmed the fact that he saw nothing off to the left. "Corporal, did you ever have a bad head injury or a period of unconsciousness because of a sickness?" "Why yes I never thought about that but I did. At the age of nine I was so very ill with meningitis, they thought I might die but I gradually came out of the stupor and went back to school." Turning to the resident, I said: "This reminds me of a patient on my TGH service a few months ago who had a seizure related to temporal lobe trauma several years before. He too was unaware of his hemianopia and had lain in a coma and then semi-stupor for several weeks after a car accident. His name was Harold Mason from Hastings Ontario." With that there was a shout from the Corporal: "Harold Mason! Hastings is my home and he is my next door neighbor!" In their (cruelly painful) air encephalograms both had atrophic temporal lobes. We calculated that they could walk quietly down their adjacent sidewalks and be unaware of each other! The resident, the patients and I profited from this experience of dramatic coincidence in Medicine. Both patients responded well to longterm anticonvulsant therapy. The resident flourished and among other things made a superb University President.

Toronto's Chief of Police, many years ago and I had a friendly professional association and on one occasion he asked me to sit with him at the Royal Winter Fair. The feature of the evening for him may have been the horses, for me it was the finals of the "Miss Canada Contest." At one point there was a rustle in the bathing suit line-up which was adjusting to the fact that from the middle of the line a contestant had broken ranks and was sitting on the edge of the stage with her feet dangling and looking a little dazed. The chief said: "What the hell?" As she was helped to the side of the stage I muttered to him "Likely a temporal lobe seizure." Next morning this young lady was sitting in one of my beds at TGH and an astute resident had a history of olfactory hallucinations, deja-vu phenomenon and was plotting correct investigation as to the cause of her temporal lobe seizure thought in time to be the result of birth injury.

The phenomenon of Transient Global Amnesia (TGA) has been a pathogenetic enigma for all the 40-odd years since its earliest description. Something happens to an individual's ability to imprint memories for a finite period of time, usually several hours and often as a sequel to emotionally stressful situations. Patients and relatives think they are acutely and suddenly developing Altzheimer's Disease and may convince less sophisticated physicians of the same. Temporal lobe epilepsy and basilar artery ischemia are also mistaken diagnoses. They exhibit only modest apparent confusion as seen by relatives but are able to perform such technical tasks as driving in traffic and not passing over red lights or driving with recklessness. The link to sexually exciting stress was made by Inzitari of Florence (Firenze). By curious coincidence this visitor shared his manuscript with me at breakfast time in my home. I had not yet made the link. Later that morning in the Clinic I saw an elderly professor who reminded me that five years before I had assured him that most people have only a single attack of amnesia and he was here to report a second event a few days previously. His worried wife was along and when he denied strenuous precipitating activity, she rushed in to correct him and to recount that on both occasions a violently exciting sexual encounter had taken place prior to both episodes.

Somewhat later I was asked to pass judgment on the suitability of an airline pilot with witnessed TGA to be in charge on the deck of jet planes. As a sequel to strenuous bedroom activity he had been thought vague by his first mate when he arrived at the pre-flight briefing. He abruptly became fully alert and aware standing in the airport medical suite. There was no memory imprinted from then back to when he shut his own door. As expected he had navigated the airport corridors and the possibility is real, but speculative that an experienced pilot could cope with airport flying routines just as another person during a TGA event might cope with heavy traffic. None thought he should be in charge on the flight-deck.

It has been alleged on anecdotal evidence that a soporific drug, Halcion, will precipitate TGA. One famous Canadian murder trial accepted that a man who took a dose of this sleeping pill, got out of bed in the middle of the night and into his car, drove across Ottawa, bludgeoned his mother-in-law with a tire iron, put the bloody metal back in his trunk parked his car in his own garage and went to his bed. He was "innocent of murder" as not fully in touch with his environment. Some of us are skeptical of the accuracy of this decision and a few more "crimes" disallowed after its use.

During my Toronto practice days I saw a large number of isolated single-nerve violent effort, entrapment and compression neuropathies. Regrettably the material never got published. One day at TGH clinic two girls, both in their early teens, presented with bilateral foot-drop and both had varying degrees of peroneal palsies. Three months previously they had begun a summer job of weeding in the vast onion fields 30 miles north of Toronto. That weekend I drove to that farm to see what toxic pesticide was at work. There was the answer: they were all squatting down, stretching their peroneal nerves at the fibular head eight to ten hours a day. Diagnosis established by a site-visit! Later I encountered a young lady from a school for cheerleaders with a peroneal palsy resulting from the prolonged posturing demanded for their elegant eye-catching prancing.

My most uncommon compression phenomenon is worthy of a summary. A young man took his friendly girl-companion to an Oshawa secluded lovers-lane. As it was cold they kept the motor running and removed what clothes were needed for their plan, 
she atop him. While they kept the car running they were prepared to ignore the faulty muffler. She recovered first and reported that the gas had run out and the motor and heater were off. It was a sub-zero night. She got to a highway for help. He was brought in to my service at TGH with bilateral complete sciatic paralysis. He was modestly hypothermic and CO damage to his brain (and hers) may have been diminished by the hypothermia (Who knows?). After two years in a rehab facility he had, (mirabile dictu) recovered most of his lost motor and sensory function. He suffered badly from anesthesia dolorosa (causalgic pain) during his recovery period. The poor man paid for his short period of pleasure with the loss of two years of his youth. I felt sad for him. His experience certainly drove home for me and my residents the vulnerability of and the closeness to the surface of the sciatic nerve. Twenty dollars for a cheap motel room would have spared him a lot of agony and embarrassment as well as a tank of gas.

Ever since my residency days when I was obliged to hold down patients while they were given electro-shock therapy (EST) I have been interested in the changing patterns of brain function by electricity and spontaneous seizures. Mood and thought processes will assuredly be altered by EST. Although the infamous use of Taser guns by police forces in subduing disturbed individuals by using a milder form of EST than was practiced in psychiatry they too have been able to cause cerebralcontrolled cardiac disturbances and in both settings cardiac arrest has been the result. This of course has been strenuously denied by those who manufacture and use Taser guns. My colleagues in our hospital epilepsy unit tell me that just occasionally the cerebral commotion of a spontaneous seizure may be followed by cardiac arrest. The most publicly acknowledged event of this type noted in the media was the death by cardiac arrest of the seizure-prone member of the famed Dionne quintuplets. Lightning strikes may be followed by cardiac arrest. A patient exhibited for me the diagonal burn about an inch wide extending from his clavicle area across his chest and abdomen and stopping at his groin: the location of the metal handle of his golf umbrella held there during a sudden lightning storm. A fellow golfer saved him from death when cardiac arrest occurred. He immediately gave vigorous CPR and started the heart. Electroshock can indeed interfere with cardiac rhythm. Maybe in the foreseeable future this will mean supplying the Royal Canadian Mounted Police with the paddles of defibrillation to go with their Taser kits.

Before moving to more distant places in these personal memories two points may be made; first is the profound effect that early medical school contacts are bound to make. I have elsewhere commented on the thrill that went through the class when our first physiology lecture was given to us by Charles Best, the co-discoverer of insulin. Later our class was enriched by two of the Toronto medial school's best teachers: William Boyd and J.C.B. Grant. They thought, taught and wrote with a clarity that remains unforgettable 60 years after leaving their classrooms. By example both inspired many (certainly I would think this includes me) to strive for professional excellence and exactitude.

The reader will recognize and must excuse many omissions from Canadian Medical schools other than Toronto or Western. They would belong on a more complete list of clinical medical contributors altering the practice of medicine. The emphasis has been focused on individuals close enough to me to be my chief sources of inspiration. Others have been discussed in earlier versions of these memoirs. Some undoubtedly were omitted in error. My intention never was to produce a "Who's Who of Canadian Medicine". 